\title{
Reexamined Structural Design Procedures for Very Flexible Aircraft
}

\author{
Carlos E.S. Cesnik* \\ University of Michigan, Ann Arbor, Michigan 48109-2140 \\ Rafael Palacios $\ddagger$ \\ Imperial College, London, England SW7 2AZ, United Kingdom \\ and \\ Eric Y. Reichenbach \\ The Boeing Company, St. Louis, Missouri 63042-2513 \\ DOI: $10.2514 / 1 . C 032464$
}

\begin{abstract}
This paper reviews the applicability of some conventional structural design practices to the analysis and design of very flexible aircraft. The effect of large structural deformations and the coupling between aeroelasticity and flight dynamics is investigated in different aspects of the aircraft structural design process, including aeroelastic stability, loads, and flight dynamics and control. This is illustrated with a numerical example of the static and dynamic responses of a representative high-altitude long-endurance vehicle. Suggestions are presented for the development of appropriate frameworks to design and analyze very flexible aircraft.
\end{abstract}

\section{Nomenclature}

C

$c$

$c_{L}$

$c_{M x, \mathrm{cg}}$

$d_{x}$

$H$

$K$

$M$

$M_{F}$

$M_{p}$

$M_{x}, M_{y}$

$R$

$s$

$T$

$t$

$U$

$u$

$V_{\mathrm{ds}}$

$V_{g}$

$v_{x}, v_{y}, v_{z}$

$x_{\mathrm{cg}}, y_{\mathrm{cg}}, z_{\mathrm{cg}}$

$\alpha$

$\beta$

$\Delta t$

$\delta$

$\delta_{\text {elev }}$

chord, $m$

lateral displacement, $\mathrm{m}$

generalized mass matrix

fuel mass, $\mathrm{kg}$

payload mass, $\mathrm{kg}$

distance, $m$

actuation time, $\mathrm{s}$

time, $s$

flight speed, $\mathrm{m} / \mathrm{s}$ respectively, $\mathrm{m} / \mathrm{s}$ frame, $m$ generalized damping matrix

wing/aircraft lift coefficient

wing/aircraft pitching moment coefficient at the aircraft's center of gravity longitudinal position

gust gradient distance, $\mathrm{m}$ generalized stiffness matrix

twist, bending moments, $\mathrm{N} \cdot \mathrm{m}$

generalized force column matrix

general control surface input

design gust velocity, $\mathrm{m} / \mathrm{s}$

discrete gust velocity, $\mathrm{m} / \mathrm{s}$

body lateral, longitudinal, and vertical velocities,

aircraft center of gravity in the body reference

Received 11 June 2013; revision received 19 January 2014; accepted for publication 30 January 2014; published online 4 June 2014. Copyright (C) 2014 by Carlos E. S. Cesnik, Rafael Palacios, and Eric Y. Reichenbach. Published by the American Institute of Aeronautics and Astronautics, Inc., with permission. Copies of this paper may be made for personal or internal use, on condition that the copier pay the $\$ 10.00$ per-copy fee to the Copyright Clearance Center, Inc., 222 Rosewood Drive, Danvers, MA 01923; include the code 1542-3868/14 and \$10.00 in correspondence with the CCC.

*Professor, Department of Aerospace Engineering; cesnik@umich.edu. Fellow AIAA (Corresponding Author)

†Reader, Department of Aeronautics; r.palacios@imperial.ac.uk. Member AIAA.

¥Technical Fellow, Boeing Research and Technology; eric.y.reichenbach@ boeing.com. Member AIAA.

$\begin{array}{lll}\delta_{\max } & =\text { maximum control surface deflection, deg } \\ \varepsilon & =\text { column matrix of beam strains } \\ \theta_{y}, \theta_{z} & =\text { roll and yaw angles, respectively, deg } \\ \lambda & =\text { aerodynamic inflow states } \\ \omega_{x}, \omega_{y}, \omega_{z} & =\text { body pitch, roll, and yaw rates, rad } / \mathrm{s} \\ (\cdot) & =\text { time derivative of the quantity }\end{array}$

\section{Introduction}

$\mathbf{M}$ ETHODOLOGIES for aircraft structural design in production environments are evolving processes that accumulate the companies' experience in previous airframes and must adapt to the novel characteristics expected in future ones. Ever since the first metallic airframe, a common characteristic on almost all built aircraft has been a relatively high stiffness; therefore, structural analysis methodologies used in their design have been mainly based on linear elastic assumptions. In recent times, extremely high-performance requirements for next-generation high-altitude long-endurance (HALE) aircraft, such as those proposed in the U.S. Air Force SensorCraft program [1] (an intelligence, surveillance, and reconnaissance unmanned aircraft), are challenging those standard methodologies as the proposed vehicles include very flexible highaspect-ratio wings [2]. Engineering analysis on very flexible vehicles will need to include geometrically nonlinear structural models for the primary structures in order to capture any large deformations that may appear under operational loads. In addition to large deformations, a second characteristic of very flexible aircraft will be very low frequencies of their natural structural vibration modes. Due to this, it should be expected a strong coupling between the structural dynamics and the rigid-body (flight dynamics) characteristics of the vehicle. As an example of this trend, Fig. 1 shows the layout of the Eta sailplane, which was designed with an aspect ratio of 51.33 (for a predicted aerodynamic efficiency of $L / D=70$ ). The photograph on the right shows a snapshot of the aircraft wing shape in a typical landing condition.

As performance requirements on military programs are specified together with ambitious sensing and reconnaissance goals, the resulting (unmanned) platforms may adopt quite unconventional configurations $[3,4]$. Design for an optimal performance of vehicle with significant flexibility effects should be based on integrated multidisciplinary analysis methodologies from an early stage in the conceptual definition of the vehicle so as to be able to exploit in a positive manner the interaction between the flexible structure, the vehicle flight performance, and the aerodynamics. 

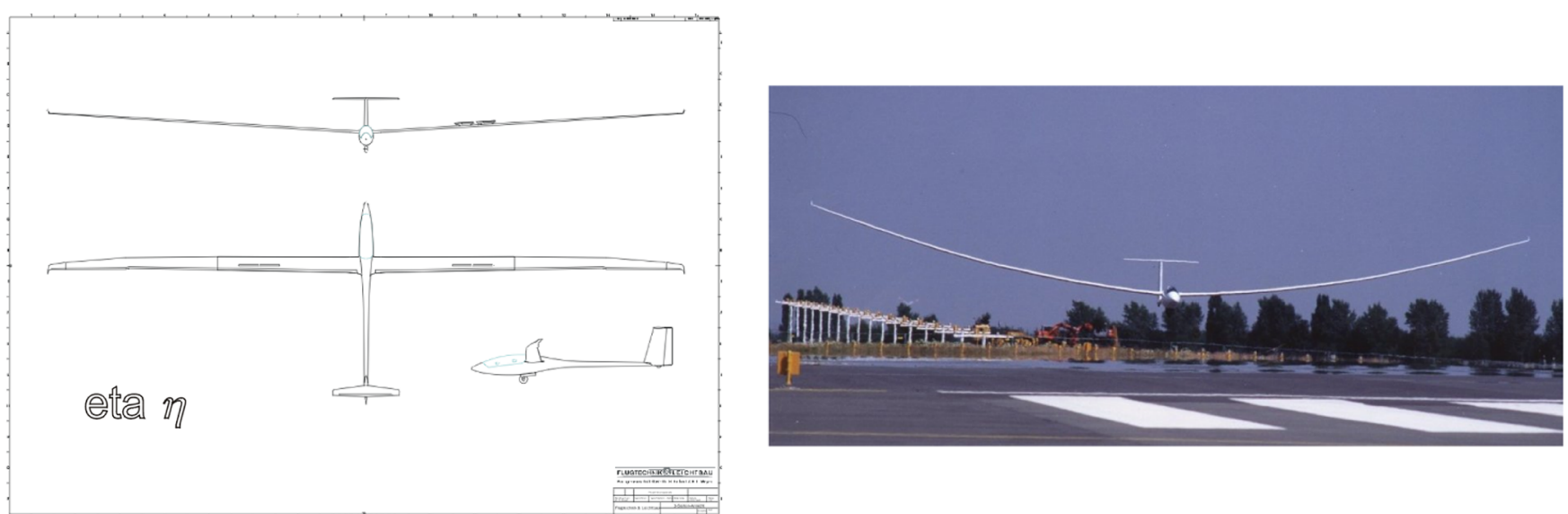

Fig. 1 Layout of the Eta sailplane and aircraft during landing (courtesy of Flugtechnik and Leichtbau).

This work aims to address some needed reinterpretation of several customary design procedures (yet, in the spirit of the civil [5] or military [6] standard practices) so as to update them to the needs of a broader, and essentially nonlinear, paradigm. This new design perspective should at least incorporate the following four basic ideas:

1) The deformed aircraft geometry, which will depend on the operating (trim) condition, should now be the baseline in weight, structural, and stability analyses.

2) Transient dynamic simulations should include large nonlinear displacements of the aircraft.

3) Aeroelastic models should incorporate rigid-body motion of the vehicle, and vice versa.

4) Flight dynamics models should incorporate nonlinear aeroelastic effects.

Concepts like flutter point and stability derivatives become flightpoint dependent (i.e., a linearization around different nonlinear equilibrium states), and their role must be redefined in the context of very flexible aircraft.

The paper presents a critical review of some key points in the structural design process and provides suggestions for the development of appropriate frameworks in which HALE aircraft design should be conducted. In particular, geometric nonlinear structural modeling and coupled nonlinear flight dynamics/aeroelastic effects can be shown to drive the need for redefinitions of some current design practices. The simulation tool of [7], the University of Michigan's Nonlinear Aeroelastic Simulation Toolbox (NAST), is used to illustrate some of these needs as applied to the preliminary design of a representative HALE aircraft. NAST models full-aircraft dynamics based on two-dimensional (2-D) incompressible unsteady aerodynamic models, geometrically nonlinear beam structural elements, and nonlinear rigid-body vehicle dynamics.

\section{Critical Review of Some Analysis Procedures}

A number of conventional analysis procedures used in aircraft structural design may be compromised when large deformations appear in any of the primary structural components. This section discusses a few of the most important ones, namely, aeroelastic stability, loads, flight dynamics, and flight control design. Starting from a brief overview of the conventional practices, we then highlight some of the critical aspects that should be reconsidered in the analysis of a very flexible aircraft.

\section{A. Aeroelastic Stability Evaluation}

Conventional practice for aeroelastic stability evaluation is based upon a combination of experimental and linear analysis techniques. Aircraft flutter and aeroelastic divergence analysis is performed via the coupling of a linear airframe finite element model with a linear oscillatory aerodynamic model. Corrections to the linear aerodynamic analysis predictions may be developed based on windtunnel pressure measurements or computational fluid dynamic analysis results. These corrections, which are based on steady conditions, are applied at both zero and nonzero reduced frequencies using a variety of schemes [8]. On larger aircraft development programs, aeroelastic wind-tunnel testing may be performed to further quantify nonlinear unsteady aerodynamic effects. A dynamically scaled model is designed to replicate the modal characteristics of the full-scale aircraft. The wind-tunnel test results are then used to calibrate aeroelastic analysis predictions. In summary, conventional practice for aeroelastic stability evaluation is based on corrected linear aeroelastic analysis techniques supplemented by aeroelastic wind-tunnel test when the expense is justified.

This traditional procedure relies on the fact that flight dynamics and aeroelastic responses have been separated by at least an order of magnitude in their frequency ranges, which effectively decouples both analyses. Very flexible aircraft will present, however, very low first natural frequencies, which will likely prevent this decoupling to occur $[7,9,10]$. In this situation, body-freedom flutter (BFF) may appear in the coupling of the first bending frequency with the short-period rigid-body mode. BFF is typically observed on flying wings or blended-wing-body configurations [11], which show both low aircraft pitch inertia and low wing bending frequencies. Moreover, the fuel fraction typically needed for longendurance flights substantially modifies the structural dynamic characteristics of the vehicle in different segments of a typical mission profile. It then becomes extremely challenging to remove the BFF from appearing within the flight envelope without penalizing performance. A practical solution, suggested in [11], is rather to actively suppress this instability by appropriate design of the flight control system.

BFF can also be the critical aeroelastic instability in other nonconventional aircraft designs, depending on the appropriate combination of fuselage pitch inertia, location of the center of gravity, and wing flexibility. Using simplified (linear) analytical estimations, Weisshaar and Lee [12] have identified the major trends for those conditions to appear on a typical joined-wing configuration. In the case of very flexible aircraft, the study of BFF is further complicated by the fact that the stability analysis should be performed on the deformed vehicle [11]. The baseline configuration is then dependent on the flight condition, and the different parameters in the analysis (location of the center of gravity, flight velocity, aircraft inertia, and natural frequencies) are all mutually dependent now. However, it is important to remark that, even though the instability occurs at nonlinear steady state conditions, the critical speed for BFF (for the case of a supercritical bifurcation) can still be determined by a series of linearized stability analyses.

Analyses procedures for more "conventional" aeroelastic phenomena, such as wing flutter, also need to be revisited for very flexible aircraft. In general, the sensitivity of the flutter characteristics of the aircraft to the reference geometry can be quite important, even for relatively small deformations (as shown, for example, in [13]). Aeroelastic stability studies need to be performed about the trimmed aircraft configuration, which will be different for each flight condition. In addition to that, geometrically nonlinear structural effects 
imply both the presence of significant in- and out-of-plane ${ }^{\S}$ wing bending displacements, even though the first ones are usually negligible with linear structural models.

To close the formulation, the geometrically nonlinear, structural model needs to be coupled with the appropriate aerodynamic solver, i.e., potential-flow theory at low flight speeds $[14,15]$ or Euler/ Navier-Stokes equations for compressible flow $[1 \overline{16}, \overline{17}]$. From this coupling, some physical phenomena can arise that do not occur under small structural displacements. This is the case of the structural washout effect on sweptback wings [18]: that is, the effective reduction of angle of attack of the sections normal to the flow due to out-of-plane wing bending deformations. It is well known [19] that it has a beneficial effect in delaying the aeroelastic divergence of the wing. However, for high-aspect-ratio swept wings in transonic flow, it has been found [16] that the washout also has a stabilizing effect in the unsteady aeroelastic response of the wing. If the wing starts aeroelastic induced undamped motions in the form of limit-cycle oscillations (LCOs), the washout generates a reduction of angle of attack toward the wingtip that modifies the distribution of pressure (and therefore of shock waves) over the wing. This new distribution has been seen to present smaller LCO amplitudes, and therefore a more benign behavior than the original one. In general, LCOs on high-aspect-ratio wings will depend on both aerodynamic and structural nonlinearities appearing in the process, and they all should be considered for the appropriate characterization of the phenomenon. It should be noted, however, that LCOs may be induced by the structural nonlinearity alone [20]. This coupling between two different nonlinear effects can present some unexpected consequences, and so Patil et al. [14], and later Kim and Strganac [21], have shown that, at speeds close to the flutter boundary, the interaction between structural and aerodynamic nonlinearities for a wing may cause subcritical limit-cycle oscillations to occur, and therefore start a potentially unstable flight condition that would not be singled out by linear theories.

\section{B. Structural Design Loads Development}

Conventional practice for structural design loads development is tailored to the subject aircraft type. When structural flexibility effects are minor, as may be the case for fighter aircraft, loads development is largely based on an analytically corrected experiment-based process. A nearly rigid wind-tunnel model built in the aircraft jig shape is instrumented for component loads and used to develop a nonlinear structural loads database covering a potentially wide range of flight speeds and angles of attack. Aeroelastic analysis is then performed using a linear airframe finite element model built to the aircraft jig shape coupled with a linear aerodynamic analysis method such as doublet lattice to calculate flex-to-rigid ratios or flexibility increments for application to the wind-tunnel measured component loads. This "flexibilized" structural loads database is incorporated into a six-degree-of-freedom flight simulation, which is then exercised for a variety of aircraft configurations and flight conditions to identify structural design loads associated with specified maneuvers. When structural flexibility effects are relatively more significant, as may be the case for commercial transports, loads development is largely based on an experimentally corrected analysis-based process. A nearly rigid wind-tunnel model built in the flexible aircraft cruise shape is instrumented for pressure distribution. The resulting test data are used to develop corrections to the predictions of the linear aerodynamic analysis methods used for aeroelastic analysis. Structural design loads are then calculated by aeroelastic analysis based on a linear airframe finite element model coupled with these corrected results from a linear aerodynamic analysis method like doublet lattice. This aeroelastic loads analysis is conducted on a variety of aircraft configurations and flight conditions and corresponds to steady trim or a snapshot during a maneuver time history as predicted by a six-degree-of-freedom flight simulation. In summary,

\footnotetext{
§In this paper, the notation "in-plane bending" refers to the wing bending in its own plane (that is, a forward-aft deformation), whereas "out-of-plane bending" refers to the wing bending normal to its own plane.
}

conventional practice for structural design loads development involves the most appropriate combination of wind-tunnel test and linear aeroelastic analysis processes.

While aeroelastic stability analyses can still be carried out on a linearized description of the aircraft dynamics (although this linearization is done about the geometrically nonlinear steady-state equilibrium), the transient dynamic response of very flexible aircraft needs in principle to be based on the time-domain solution of the nonlinear equations of motion. This approach has been followed in [22-24] to study the low-speed dynamics of very flexible aircraft approaching a discrete gust. Those full-aircraft dynamic simulations were based on simplified 2-D unsteady aerodynamic models [25] that needed to be complemented by aerodynamic stall models to account for the significant twist deformations appearing on the wings. They also showed strong interactions appearing between the flight dynamics and the structural response. In particular, for the unswept flying wings analyzed in $[23,24]$, it was found that an unstable pitch response appears when the vehicle hits a gust of moderate intensity.

Geometrically nonlinear, wing deformations may also have an important contribution in aircraft dynamic response to ground loads. This needs to be investigated in some critical cases, such as aircraft landing impact loads, where large wing deformations might absorb a significant part of the impact energy. In general, main airframe flexibility affects the dynamic response of landing gear [26], and so the fuselage flexibility is usually introduced in landing gear simulations through some modal reduction technique, such as CraigBampton modes. This approach is, however, based on a linear model for the mainframe structural dynamics and would need to be updated to consider large structural deflections on the structure. A possible solution would be to couple the detailed landing gear model with a reduced nonlinear structural model for all primary mainframe components (such as those proposed in [ㄱ, 22] ).

\section{Flight Simulation Development}

Conventional practice for flight simulation development accounts for airframe flexibility effects via linear aeroelastic analysis predictions. As in the case of wind-tunnel measured structural loads, wind-tunnel measured aerodynamic stability and control databases are flexibilized using flex-to-rigid ratios or flexibility increments determined by linear aeroelastic analysis. These flexibility effects are incorporated into the six-degree-of-freedom flight simulation such that predicted maneuver trajectories are affected. This conventional practice is based on the assumption that flexibility effects are minor (stability, control, and load derivative flex-to-rigid ratios are close to unity) and that airframe structural modes do not significantly affect vehicle flight dynamics.

For a very flexible aircraft, the stability derivatives used in flight dynamic simulations will be very much dependent of the aircraft trimmed shape. They should be estimated after the static aeroelastic model of the aircraft has been trimmed and will vary along the different mission points, and possibly even during maneuvers. Large structural deformations also bring some new effects into play, such as the wash-in that the torsional moments created by the drag forces create at the tip of wings with large bending deformations [9].

As a result of flight dynamic analysis, aircraft load and balance diagrams [18] are defined to provide management procedures for fuel and payload location that yield safe margins for vehicle operation. For a given total mass of the aircraft, minimum and maximum locations of the center of gravity (c.g.) are determined in all three spatial directions. Shifting of the c.g. affects, in general, the stability and control characteristics, the distribution of loads among front and rear landing gear in ground operation, and the intensity of the maneuvering loads appearing on the aircraft tail. In the case of very flexible aircraft, large structural deformations will change the location of the c.g., and this could be a critical contribution to the operational characteristics of the vehicle. The actual c.g. location at any time will be defined not only by the amount of remaining fuel but also by the current aircraft geometry: whether the aircraft is in steady flight or in maneuvering conditions, or in low- or high-altitude flight. These will determine the current distribution of the structural weight 
(as well as the effects of other components such as wing-mounted engines or wing fuel tanks). For aircraft with unswept wings, there will be essentially a vertical c.g. shift due to wing flexibility in steady flight conditions, whereas for aircraft with high-aspect-ratio swept wings, the c.g. shifting in steady flight will also occur along the axis of the fuselage.

There are at least two ways to address the effect of aircraft flexibility in its balance diagrams: First, one can define safety margins in the aircraft weight distribution limits that account for the expected maximum contributions of the in-flight vehicle deformations to the c.g. location. This approach would not modify the essential weight analyses procedures, which would still be based on the undeformed aircraft geometry. Second, one can compute the critical weight distributions based on actual operating conditions that include the deformed aircraft geometry. In this case, for a given payload and fuel distribution (that is, a given c.g. location in the undeformed aircraft), the possible actual weight distributions due to different structural deformations should be studied. For each possible weight distribution, the corresponding aircraft stability analysis should be performed to identify critical conditions. That will either result in weigh clearance or limit the current payload and fuel distribution.

It is important to emphasize that the weight optimization process of flexible aircraft (and especially for large aircraft) needs to consider, from an early stage in the design process, the impact of the vehicle flexibility in its actual performance [27]. In this respect, aeroelastic phenomena should not be analyzed a posteriori once the basic aircraft layout is fixed, as this could dramatically penalize either the performance or the structural weight on the final design.

Finally, it should be noted from a numerical analysis point of view that, while flight dynamics of flexible aircraft in the linear range can assume a fixed location of the c.g. within the aircraft, numerical simulation of the flight dynamics of very flexible aircraft should use as reference some fixed point of the vehicle (for instance, the initial location of the c.g. or the location of the inertial measurement unit) $[\underline{7}, \underline{28}]$.

\section{Flight Control Development}

Conventional practice for flight control law development addresses the aeroservoelastic stability of rigid and flexible airframe modes using an aeroelastic state-space model derived using a linear airframe finite element model and a linear unsteady aerodynamic analysis method, as is done for aeroelastic stability evaluation. Techniques such as rational function approximation are used to convert the unsteady aerodynamic forces from frequency to time domains. If structural and flight dynamic mode frequencies are well separated, as may be the case for fighter aircraft, the aeroelastic statespace model may contain structural mode states only, and thus ignore coupling with rigid-body modes completely. Such a model is coupled in parallel with the six-degree-of-freedom flight simulation model of the aircraft. If structural and flight dynamic mode frequencies are not well separated, as may be the case for commercial transports, the aeroelastic state-space model retains both rigid and flexible mode states and their associated coupling terms as predicted by linear aeroelastic analysis. Corrections to the rigid-body portions of this coupled aeroelastic state-space model may be made to improve correlation with the six-degree-of-freedom flight simulation aerodynamic database. In either case, flight control laws are designed with structural mode filters if required to attenuate flexible mode response without violating flight dynamic phase margin requirements. In summary, corrected linear aeroelastic state-space models are used, sometimes in conjunction with linear models derived from nonlinear flight simulations, as the basis for conventional flight control design.

Some attempts $[29,30]$ have been recently made to design flight laws for a nonlinear aeroelastic vehicle, but they are mostly restricted to a local linearization around a trim position. An identification of the most appropriate nonlinear control schemes throughout different mission profiles for a very flexible aircraft is an open research topic.

\section{Numerical Example}

A low-order simulation tool (NAST) has been developed in MATLAB for the analysis of full-aircraft configurations at low flight speeds $[\underline{7}, \underline{28}, \underline{31}]$. It couples aerodynamic, structural, and flight mechanics models of the vehicle. Aerodynamic forces in lifting surfaces are modeled using finite-state 2-D incompressible unsteady aerodynamics with a simple threshold-based stall model and tip corrections. Determination of lift and moment generated by deflecting discrete control surfaces is done based on the geometric constants in [32]. The structure is characterized by a strain-based geometrically nonlinear, structural beam, finite element model, and all this is coupled with the six degree of freedom's flight dynamics of the vehicle. NAST can also model control surfaces and airfoil drag through aerodynamic coefficients, nonstructural masses, thrust, and gravity forces. The governing equations of motion have the form

$$
\begin{gathered}
M(\varepsilon)\left\{\begin{array}{l}
\ddot{\varepsilon} \\
\dot{\beta}
\end{array}\right\}+C(\varepsilon, \dot{\varepsilon}, \dot{\beta})\left\{\begin{array}{l}
\dot{\varepsilon} \\
\beta
\end{array}\right\}+K\left\{\begin{array}{l}
\varepsilon \\
0
\end{array}\right\}=R(\varepsilon, \dot{\varepsilon}, \beta, \lambda, u), \\
\dot{\lambda}=L(\dot{\varepsilon}, \ddot{\varepsilon}, \beta, \dot{\beta}, \lambda)
\end{gathered}
$$

where $\varepsilon$ represents the strain distribution on the one-dimensional structural elements, $\beta$ includes the six rigid-body degrees of freedom of the vehicle, $\lambda$ are the aerodynamic states, and $u$ are the control surface inputs. Arbitrary spatial constraints to the vehicle deformation are imposed via Lagrange multipliers. This results in a comprehensive solver to analyze the flight performance of generic high-aspect-ratio-wing aircraft. NAST is used here to illustrate the nonlinear aeroelastic effects on a wing-body-tail aircraft configuration with slender wings (aspect ratio $=33.33$ ). A view of the aircraft is presented in Fig. 2. The fuselage is modeled as a rigid and nonlifting body with a total length of $28.5 \mathrm{~m}$ and total empty mass of $1750 \mathrm{~kg}$, which is assumed to be uniformly distributed along its axis. The rest of the subcomponents, i.e., wings, horizontal tailplanes (HTP), and vertical tailplane (VTP), are flexible lifting surfaces. Their geometric properties are given in Table $\underline{1}$, and their crosssectional (structural) and aerodynamic properties are included in Tables $\underline{2}$ and $\underline{3}$, respectively. A distributed nonstructural mass of $220 \mathrm{~kg}$ is added along the axis of each wing. Linear interpolation defines intermediate values between the root and tip values given in the tables.

The basic mass (weight) breakdown of the vehicle is presented in Table 4, including the sum of structural and nonstructural masses of the different aircraft components (basic empty weight); the payload $M_{P}$, which is assumed to be located at the fuselage axis $5 \mathrm{~m}$ ahead of the wing axis (the origin of coordinates in Fig. 2); and the fuel stored in the aircraft wings $M_{F}$. The fuel is distributed along the wings following a linear variation from the root (relative value 1 ) to the point at $40 \%$ of the semispan (relative value 0.7 ).

The major structural components of the vehicle (wings, tails, and fuselage) are modeled using constant-strain beam finite elements along their respective reference axes. The wing discretization has nine elements along the span, whereas each tail has five elements. Rigid elements are defined along the fuselage to simplify the analysis. Six inflow states are used to define the 2-D finite-state

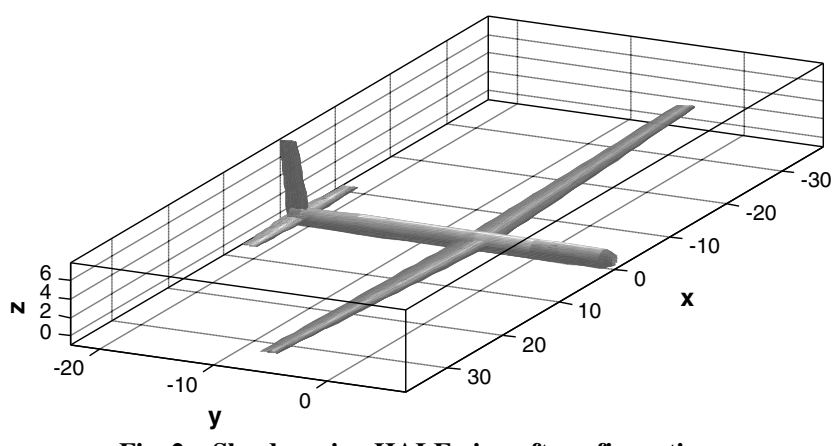

Fig. 2 Slender-wing HALE aircraft configuration. 
Table 1 Geometric properties for slender-wing aircraft

\begin{tabular}{lc}
\hline \hline Property & Value \\
\hline Wingspan & $75 \mathrm{~m}$ \\
Wing root chord & $3 \mathrm{~m}$ \\
Wingtip chord & $1.5 \mathrm{~m}$ \\
Wing area & $168.75 \mathrm{~m}^{2}$ \\
HTP span & $18 \mathrm{~m}$ \\
HTP root chord & $2 \mathrm{~m}$ \\
HTP tip chord & $1.2 \mathrm{~m}$ \\
Wing-to-HTP distance & $15.5 \mathrm{~m}$ \\
VTP span & $8 \mathrm{~m}$ \\
VTP root chord & $2 \mathrm{~m}$ \\
VTP tip chord & $1.5 \mathrm{~m}$ \\
Wing-to-nose distance & $12 \mathrm{~m}$ \\
\hline \hline
\end{tabular}

Table 2 Cross-sectional properties for slender-wing aircraft

\begin{tabular}{lccc}
\hline \hline & Wing & HTP & VTP \\
\hline Material & AL 6061-T6 & AL 6061-T6 & AL 6061-T6 \\
Reference axis(chord fraction) & 0.45 & 0.3 & 0.3 \\
Root skin/spar thickness, mm & 1.8 & 1.2 & 1.2 \\
Tip skin/spar thickness, mm & 1.0 & 1.0 & 1.0 \\
Spar location (chord fraction) & 0.45 & 0.45 & 0.45 \\
\hline \hline
\end{tabular}

Table 3 Aerodynamic properties for slender-wing aircraft

\begin{tabular}{lccc}
\hline \hline & Wing & HTP & VTP \\
\hline Airfoil & NACA 4415 & NACA 0012 & NACA 0012 \\
Incidence angle, deg & 2.0 & -2.0 & 0 \\
$\begin{array}{l}\text { Control surface location } \\
\text { [start-end], m }\end{array}$ & {$[20.83-29.17]$} & {$[1.8-9.0]$} & {$[1.6-6.4]$} \\
$\begin{array}{l}\text { Control surface chord } \\
\text { (chord fraction) }\end{array}$ & 0.2 & 0.2 & 0.2 \\
\hline \hline
\end{tabular}

Table 4 Vehicle mass breakdown

\begin{tabular}{lc}
\hline \hline Component & Mass, $\mathrm{kg}$ \\
\hline Basic empty mass & 4000 \\
Maximum payload & 1000 \\
Maximum fuel load & 2500 \\
Maximum takeoff mass & 7500 \\
\hline \hline
\end{tabular}

aerodynamic model on each structural node on the lifting surfaces. A cutoff stall angle is set at $12 \mathrm{deg}$. Numerical analyses on this configuration are performed at sea level and for varying flight velocity $U$. For each combination of flight velocity, payload, and fuel mass, the aircraft is trimmed at level flight by setting the appropriate values to the deflection control surfaces. Thrust is assumed to be an applied force on the aircraft center of gravity that compensates the horizontal forces on the trimmed condition (i.e., aircraft engines were not explicitly defined in the model).

Surface deflections at different trimming conditions are shown in Fig. 3 for (geometrically nonlinear) flexible and rigid vehicles. The corresponding wingtip displacements for the flexible aircraft in trim are included in Fig. 4. Note that, for the fully loaded aircraft, wingtip vertical deflections are around $25 \%$ of the wing semispan, and significant geometric nonlinear effects will appear. Unfortunately, the current version of NAST does not yet perform linear static analysis of full vehicles (although it does solve linear dynamic cases), and no direct comparison of the trimmed linear and nonlinear flexible aircraft can be presented in this paper. It should be remembered, however, that the limit for applicability of linear beam models in bending alone is usually at approximately $15 \%$ tip displacement.

\section{A. Longitudinal Stability Derivatives}

The longitudinal stability derivatives around the trimmed equilibrium are first computed. Figure 5 shows the derivatives of lift and pitch moment with body angle of attack, whereas Fig. 6 shows their derivatives with a symmetric deflection of the elevators. Results in the figures compare a rigid aircraft model with a (geometrically nonlinear) flexible model. Note that, as the wing deforms (larger payload or fuel mass), there is a drop in $\mathrm{d} c_{L} / \mathrm{d} \alpha$, which would not be observed in a rigid aircraft flying at the same conditions. Also, large aircraft deformations have a noticeable impact in the final distribution of aerodynamic loads, and the different stability derivatives show a much larger variation within the flight envelope. For example, the value of $\mathrm{d} c_{M x, \mathrm{cg}} / \mathrm{d} \alpha$ is essentially independent of the value of the payload (assumed at fixed location $5 \mathrm{~m}$ ahead of the wing axes, as defined previously) for a rigid aircraft. The point of neutral stability $\left(\mathrm{d} c_{M x, \mathrm{cg}} / \mathrm{d} \alpha=0\right)$ at zero fuel weight as a function of the payload is then at $-92.6 \mathrm{~kg}$ (!) for all flight speeds, whereas for the flexible aircraft, the minimum payload for a longitudinal statically stable vehicle ranges from $-70.5 \mathrm{~kg}$ at $U=25 \mathrm{~m} / \mathrm{s}$ to $23.1 \mathrm{~kg}$ at $U=40 \mathrm{~m} / \mathrm{s}$. Finally, it should be remarked that, if the location of the payload center of gravity were shifted toward the aircraft nose, the longitudinal static stability would be adversely affected. In this case, including the flexibility of the aircraft in the analysis would be critical to allow certain weight configurations.

\section{B. Open-Loop Transient Response}

Transient dynamic results are now presented for this configuration under prescribed deflections of the control surfaces. Aileron and elevator "1-cos" doublet maneuvers are defined on the trimmed aircraft for steady flight at full nominal weight $\left(M_{P}=1000 \mathrm{~kg}\right.$; $M_{F}=2500 \mathrm{~kg}$ ) and $U=35 \mathrm{~m} / \mathrm{s}$. The control input is defined as in Fig. 7, with $\delta_{\max }$ being maximum deflection and $T$ the actuation time. Three models are used to study geometrically nonlinear structural effects in the dynamic response, namely, a nonlinear flexible model,
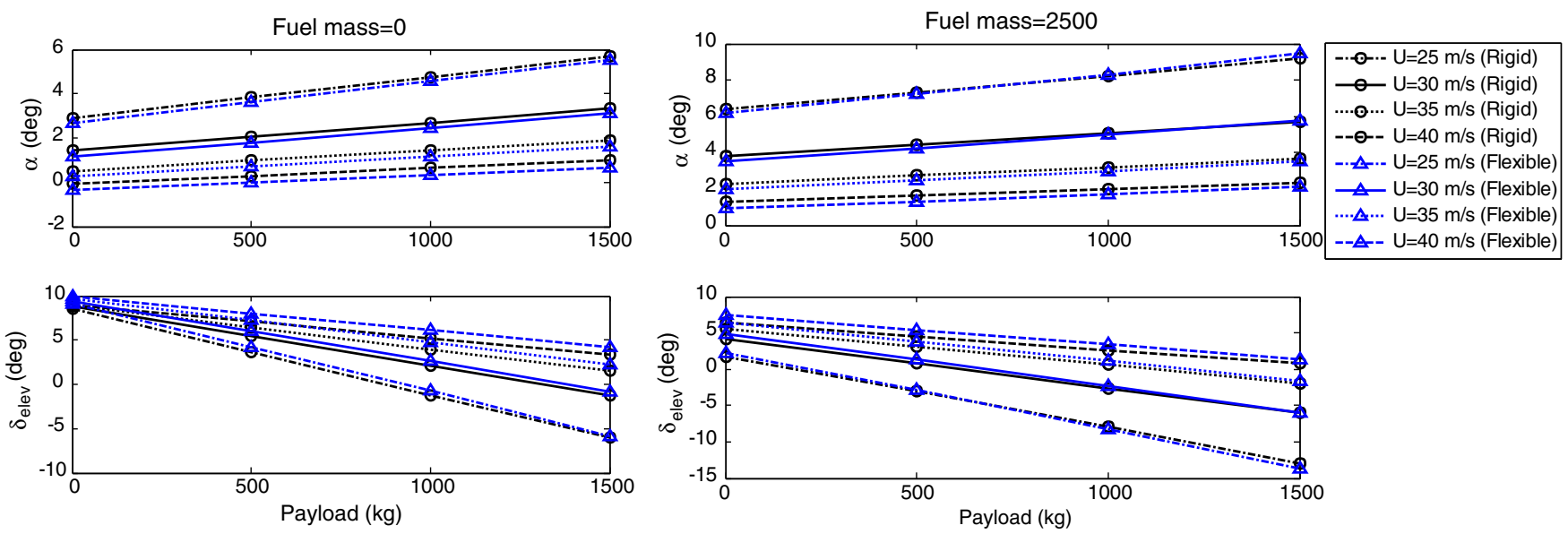

Fig. 3 Control surface deflection in trim. 


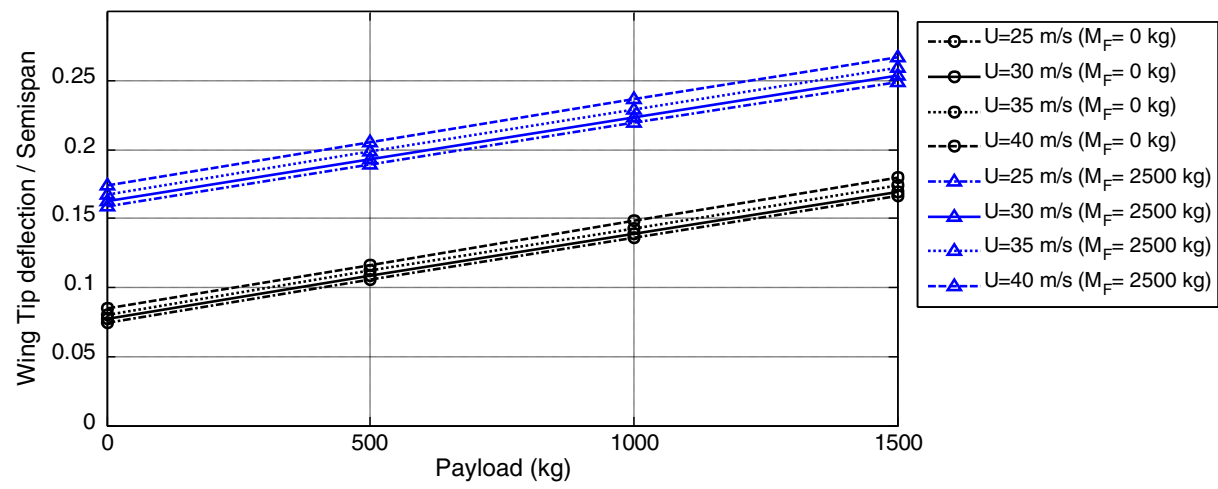

Fig. 4 Wingtip deflection in trim (flexible aircraft).
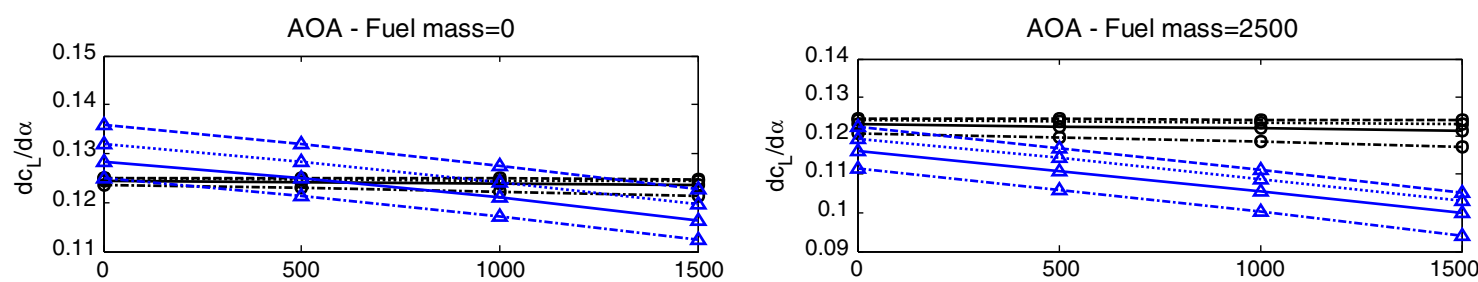

- - - - $U=25 \mathrm{~m} / \mathrm{s}$ (Rigid) - $U=30 \mathrm{~m} / \mathrm{s}$ (Rigid) ……U $=35 \mathrm{~m} / \mathrm{s}$ (Rigid) - - - $U=40 \mathrm{~m} / \mathrm{s}$ (Rigid) - $\triangle--U=25 \mathrm{~m} / \mathrm{s}$ (Flexible) $\triangle \mathrm{U}=30 \mathrm{~m} / \mathrm{s}$ (Flexible)
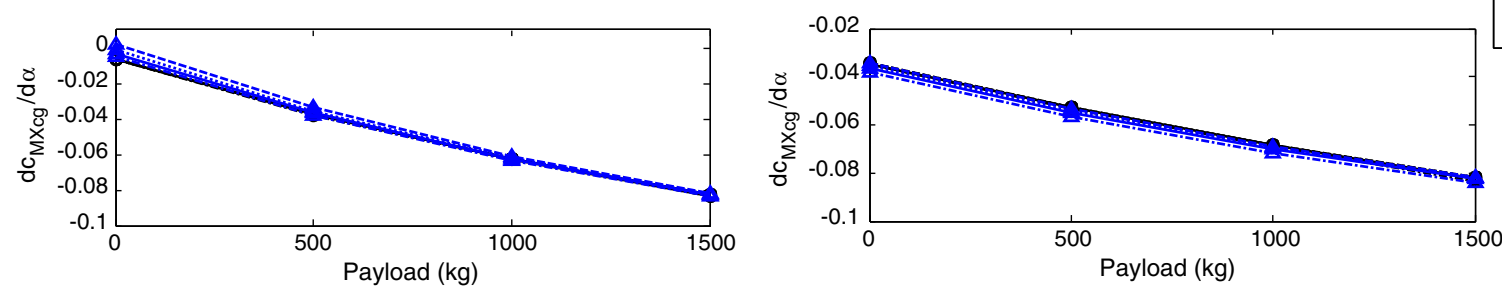

$\therefore \Delta \cdots=35 \mathrm{~m} / \mathrm{s}$ (Flexible) $--\triangle-\mathrm{U}=40 \mathrm{~m} / \mathrm{s}$ (Flexible)

Fig. 5 Stability derivatives in trim with vehicle angle of attack (AOA).
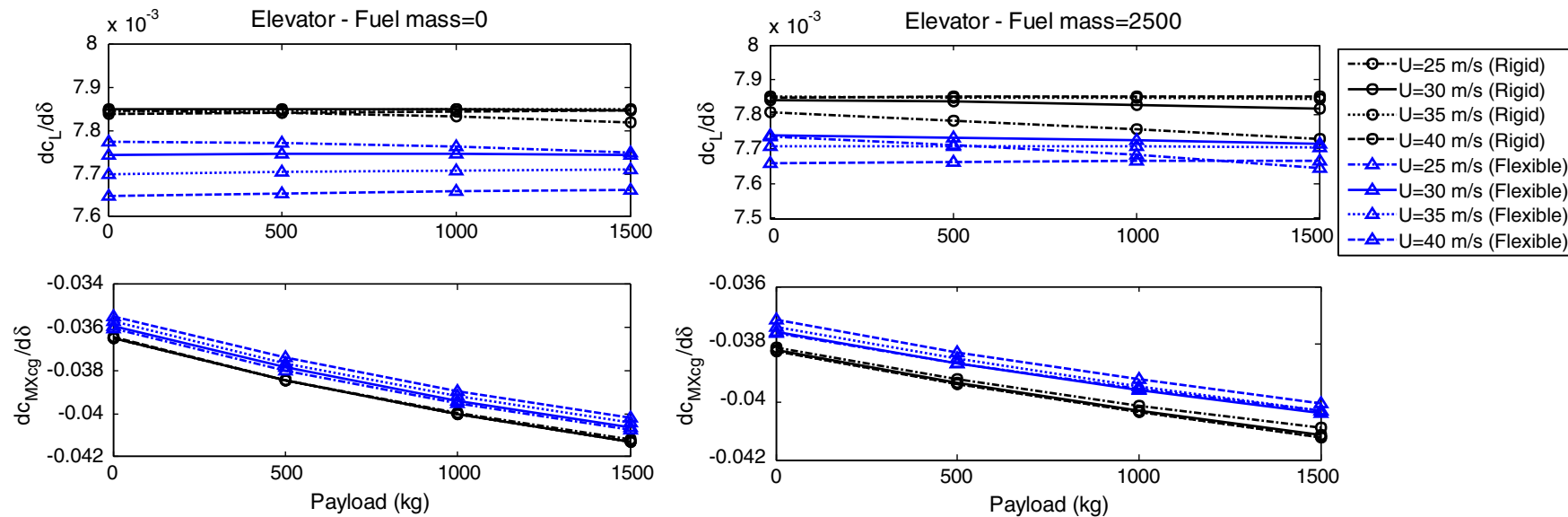

Fig. 6 Aircraft stability derivatives with elevator deflection.

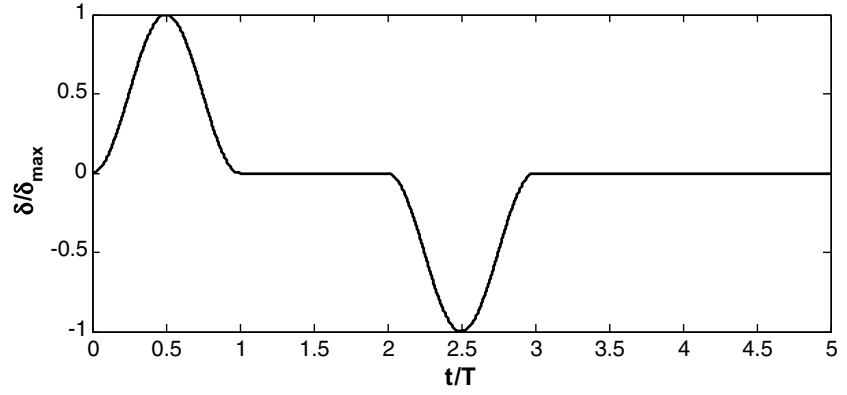

Fig. 7 Control surface deflections in a 1-cosine doublet input. a linearized flexible model, and a rigid model of the vehicle Numerical integrations were performed with an error-bounded modified Newmark method and, unless otherwise stated, the integration time step is $\Delta t=T / 100$.

In all cases, the transient response is computed from the geometrically nonlinear static deformed state of the vehicle. In the rigid-model simulations, the vehicle shape during the dynamic analysis is fixed to be the one obtained from the static analysis; in the linear flexible model, the dynamics equations [Eq. (1)] are linearized around the nonlinear steady state and, in the nonlinear model, the complete set of nonlinear equations is integrated at each time step.

Figure 8 shows the time evolution of the nonzero body-frame translational and rotational velocities at the point where the payload is located (i.e., the origin in Fig. 2 for the undeformed configuration). 

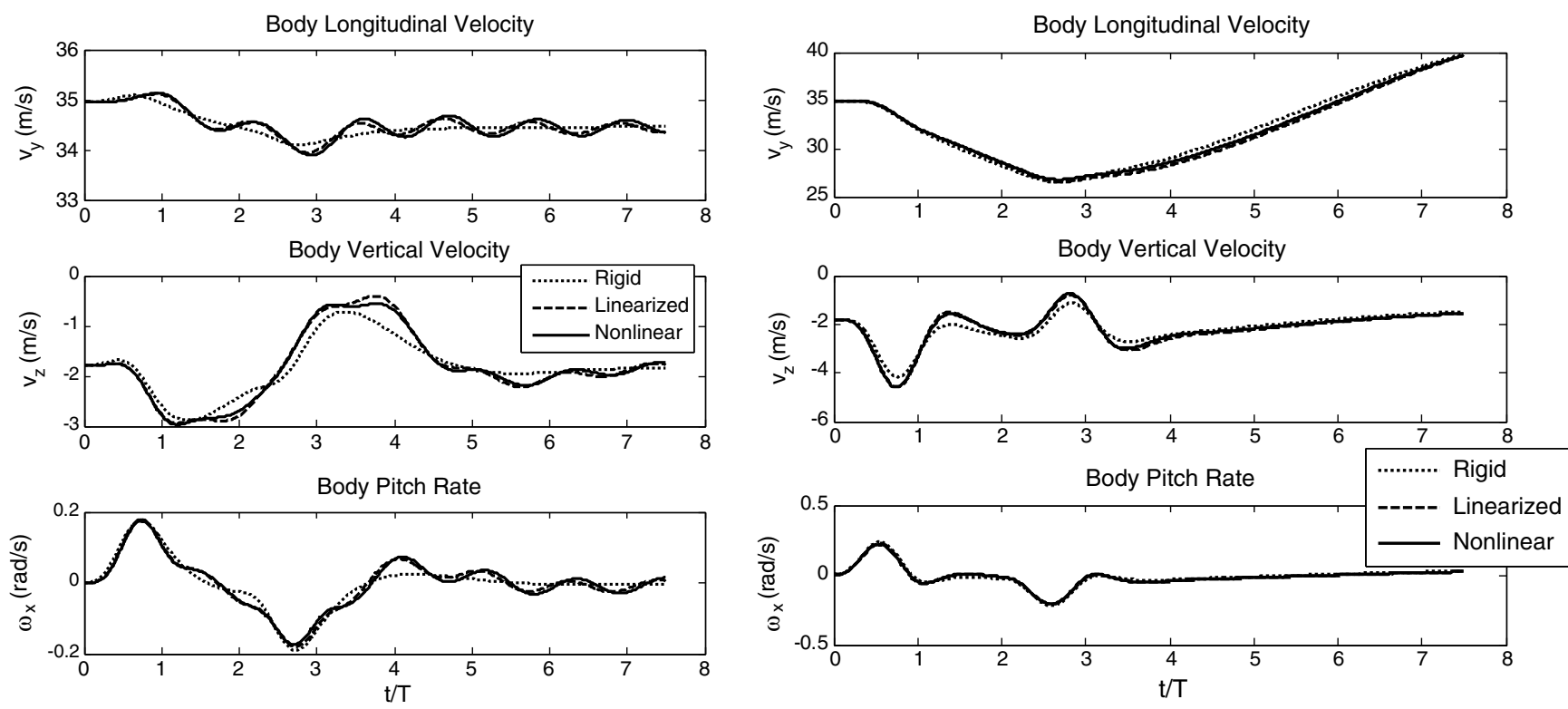

$\mathbf{T}=1 \mathrm{~s}$

$\mathbf{T}=\mathbf{2} \mathrm{s}$

Fig. 8 Body-frame longitudinal velocities for elevator deflection $\left(\delta_{\max }=-20 \mathrm{deg}\right)$.
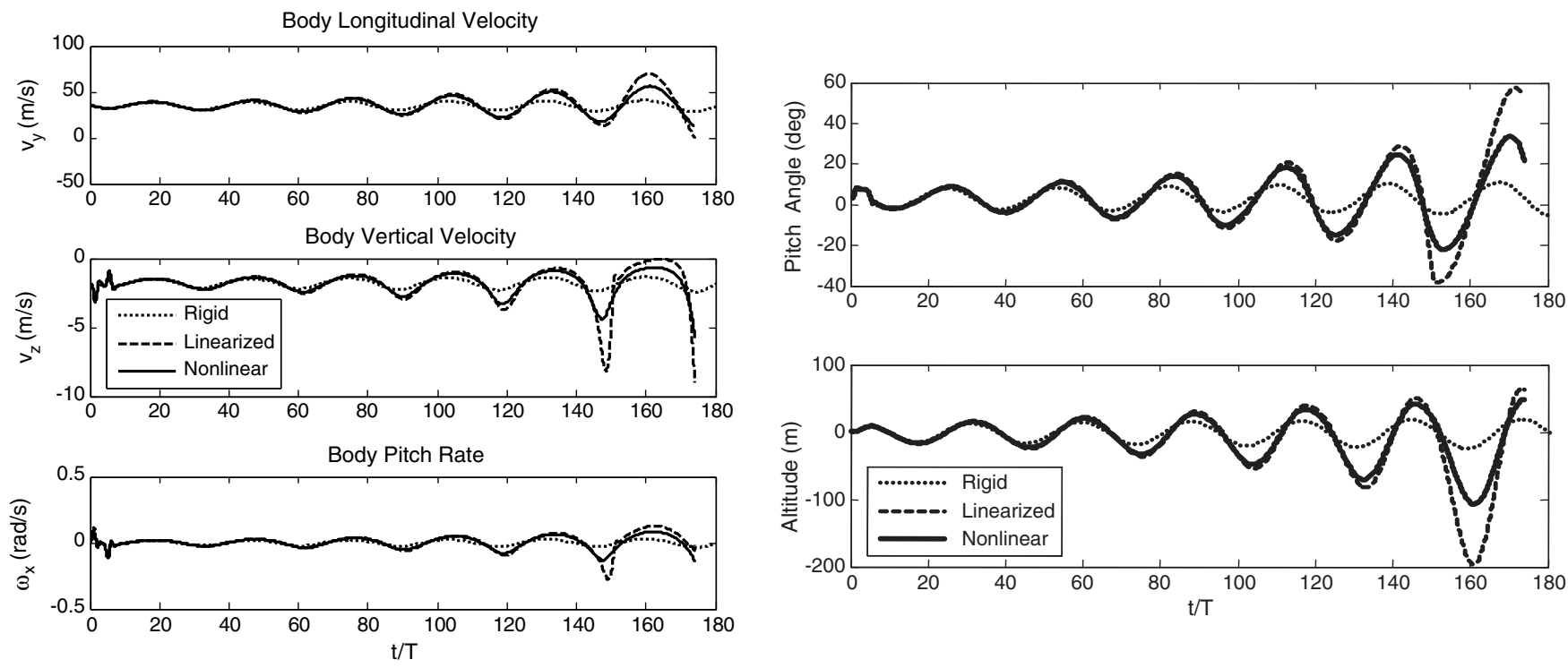

Fig. 9 Unstable phugoid mode induced by elevator deflection $\left(T=2 \mathrm{~s}, \delta_{\max }=-20 \mathrm{deg}, \Delta t=0.04 \mathrm{~s}\right)$.

The excitation is an elevator deflection of $\delta_{\max }=-20 \mathrm{deg}$ (elevators in right and left tails having equal deflection) and two different actuation times: $T=1 \mathrm{~s}$ and $T=2 \mathrm{~s}$. As can be seen, including aircraft flexibility does modify the response of the vehicle, and this effect becomes more apparent as the frequency of the excitation gets into the range of the natural frequencies of the structure. There is a $17 \%$ and a $12 \%$ increase in the peak-to-peak body vertical velocity from the rigid to the linearized and nonlinear structural model, respectively, for actuation time $T=1 \mathrm{~s}$. However, the initial response has relative small structural deformations and the geometrically nonlinear effects do not have a significant contribution.

The situation is quite different in the long-term dynamic response to the elevator doublet. As can be seen in Fig. 9, this vehicle has entered an unstable phugoid mode of frequency $0.035 \mathrm{~Hz}$. This mode is lightly undamped for the rigid aircraft model, whereas a flexible aircraft shows a much clearer faster divergent behavior. Therefore, although the long-term response is essentially dominated by the rigid-body characteristics of the vehicle, the flexible deformations of the aircraft play a very important role in the rate of divergence of the unstable phugoid mode. This can be explained as a quasi-static variation of the aircraft geometry as the amplitude of the unstable phugoid mode increases. The variations of aircraft velocity along each phugoid loop produce a change in the aircraft lift distribution, and therefore a (quasi-static) change on the wing shape, and in particular of the local angle of attack of its airfoils. Since this is a straight wing, with the elastic axis aft the aerodynamic center, this has a positive-feedback effect on the aircraft response, and therefore works toward increasing the rate of divergence of the unstable phugoid mode. Changes of wing bending deformation also contribute to this feedback loop (in a beneficial way this time), but this is not as important as the effect of angle of attack. Finally, the geometrically nonlinear structural corrections reduce the amplitude of the oscillations predicted by the linear structural model. It is yet to be seen if these nonlinear terms would eventually bound the aircraft dynamic response into a well-defined limit-cycle oscillation.

Consider now the transient dynamics for an antisymmetric deflection of the ailerons on right and left wings, and defined as 

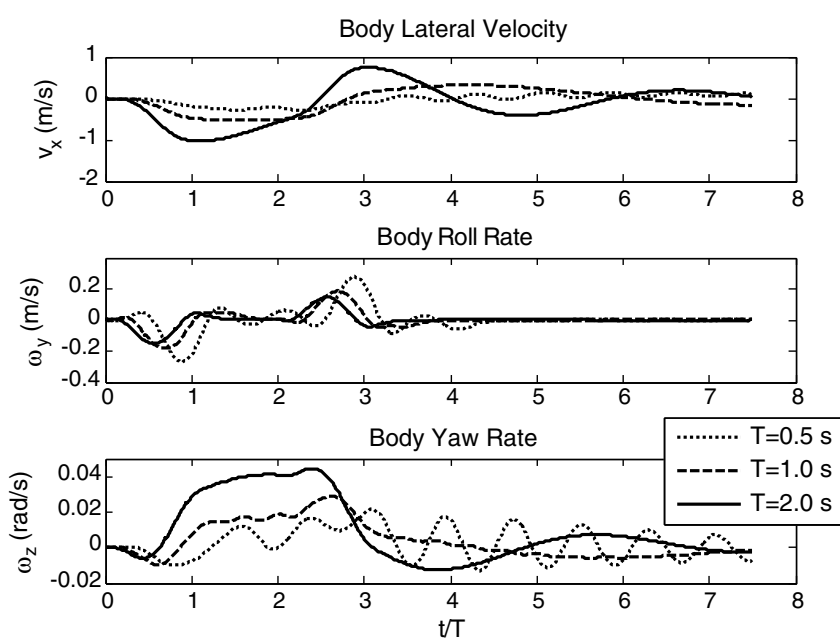

Fig. 10 Lateral response to aileron deflection on flexible aircraft $\left(\delta_{\max }=30 \mathrm{deg}\right)$.
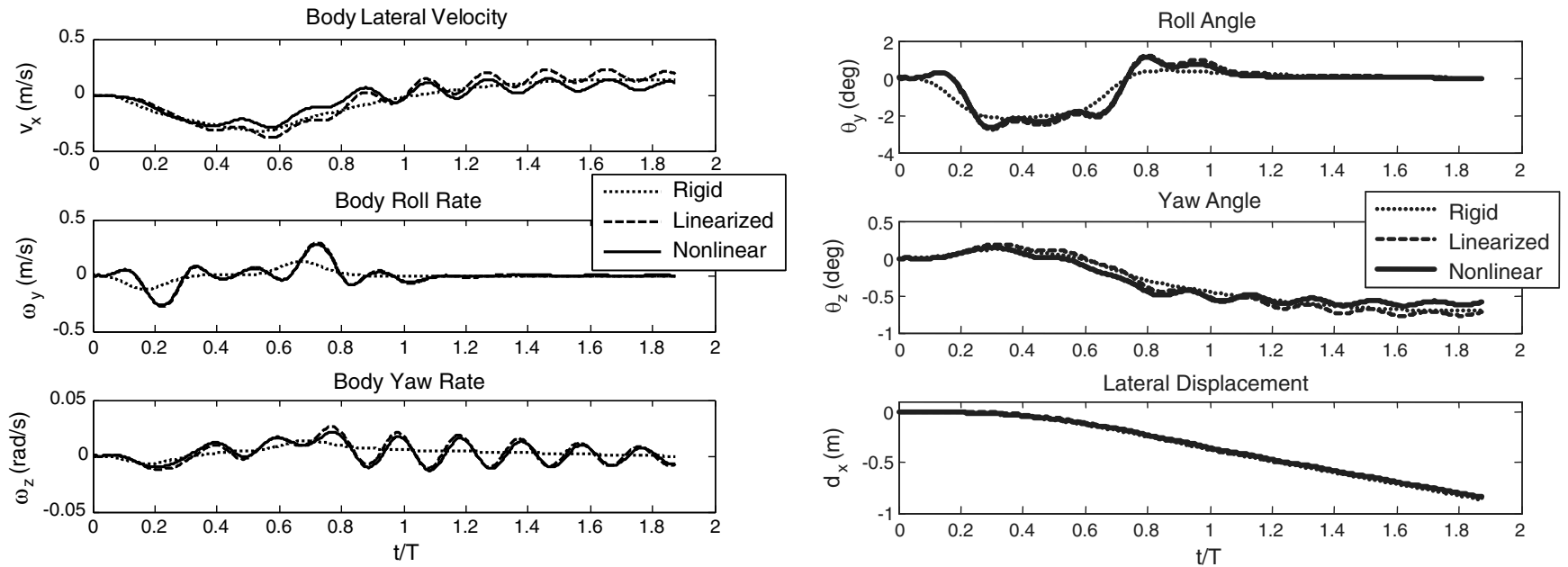

Fig. 11 Lateral response to aileron deflection $\left(T=0.5 \mathrm{~s}, \delta_{\max }=30 \mathrm{deg}\right)$.
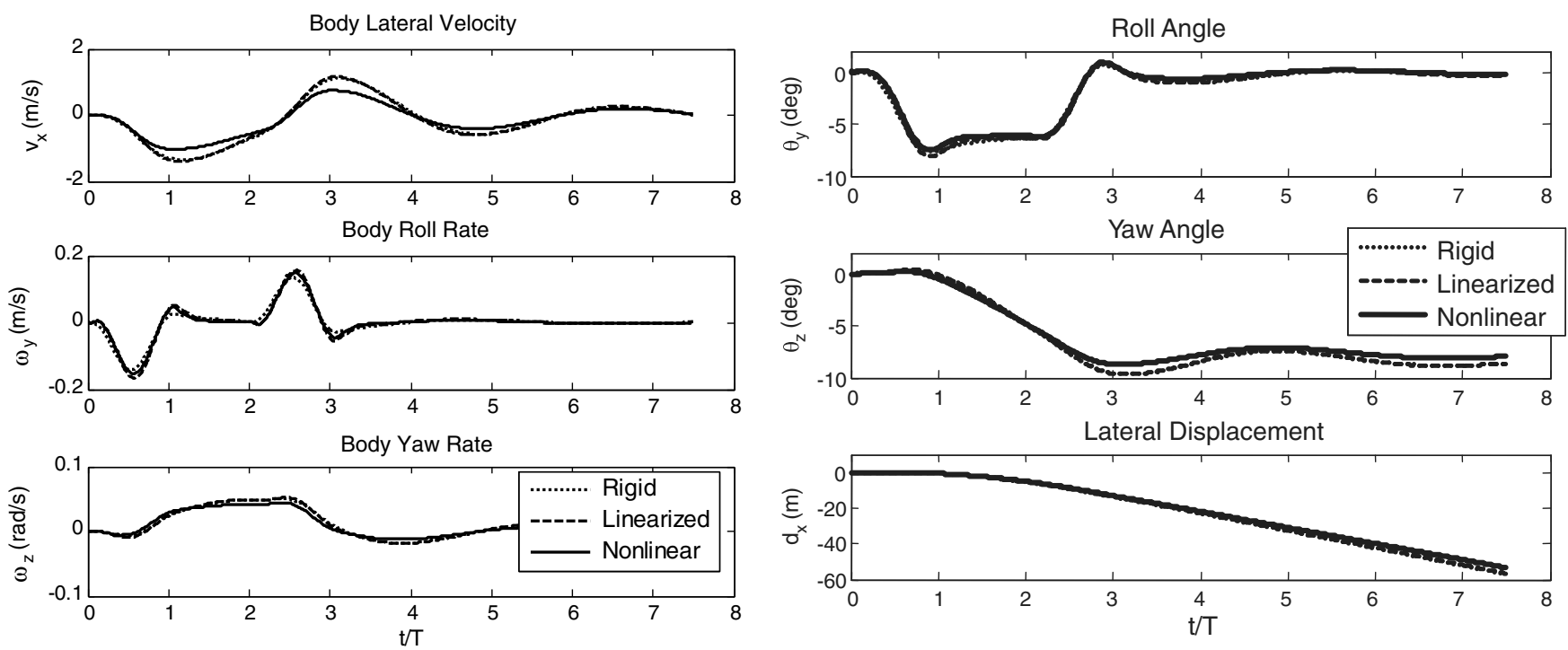

Fig. 12 Lateral response to aileron deflection $\left(T=2.0 \mathrm{~s}, \delta_{\max }=30 \mathrm{deg}\right)$.

before by the doublet of Fig. 7. The nonzero displacements, rotations, and velocities in the full nonlinear response of the vehicle for $\delta_{\max }=$ $-30 \mathrm{deg}$ and under three actuation times $(T=0.5,1$, and $2 \mathrm{~s})$ are included in Fig. 10. Note that the vehicle recovers the equilibrium very quickly, except that, at the end of the maneuver, it has changed the trajectory yaw angle. In addition, there is a delay appearing in the roll rate for smaller times.

As before, the contribution of the structural dynamics to the flight dynamics of the vehicle becomes more important at higher excitation frequencies. This can be observed in Figs. 11 and $\underline{12}$, where the 

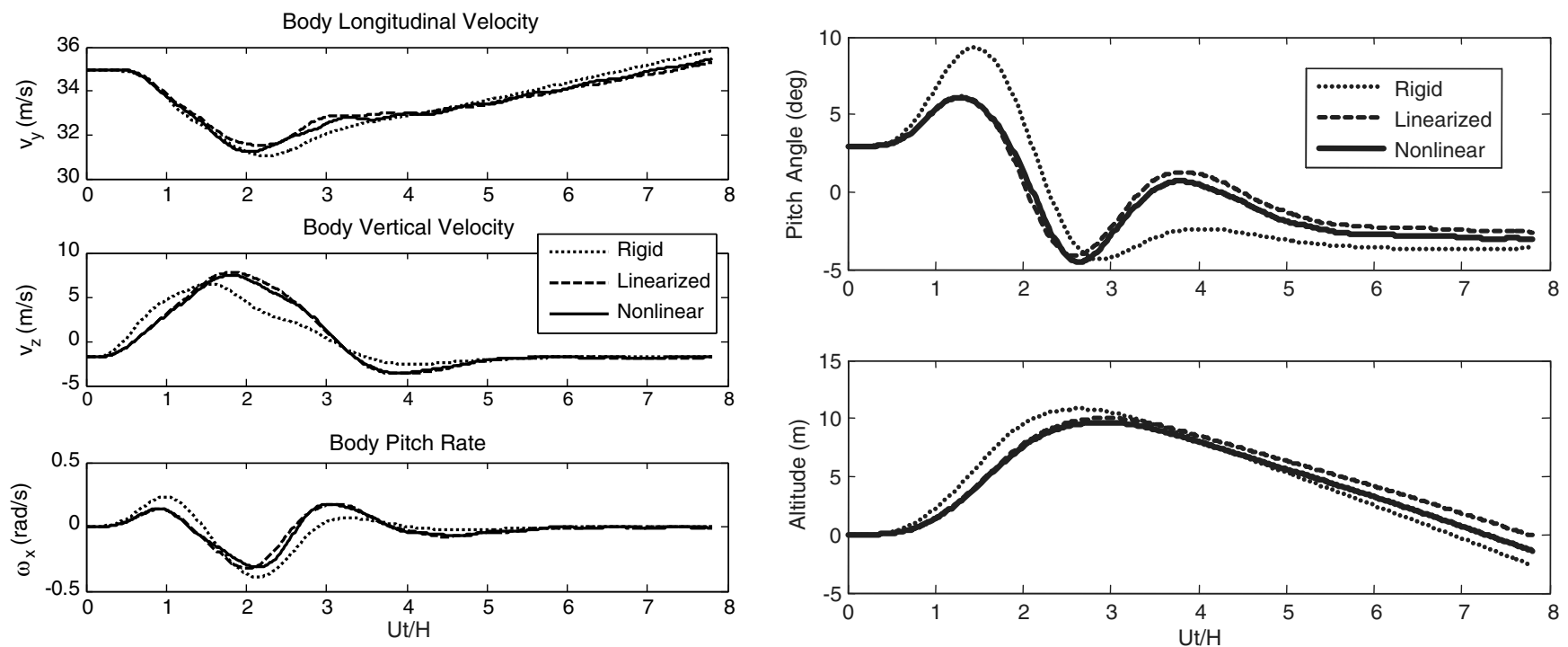

Fig. 13 Longitudinal response to symmetric discrete gust $(U=35 \mathrm{~m} / \mathrm{s}, H=25 \mathrm{~m})$.
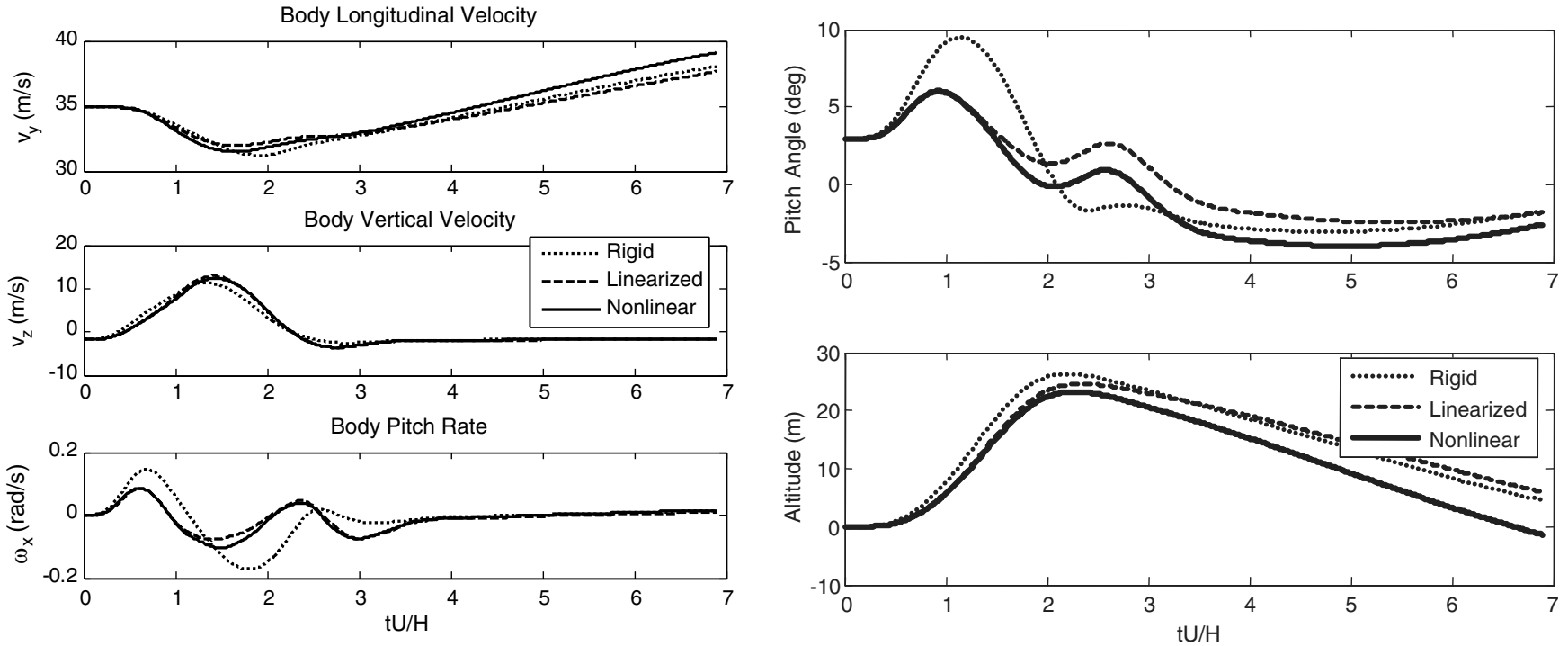

Fig. 14 Longitudinal response to symmetric discrete gust $(U=35 \mathrm{~m} / \mathrm{s}, H=50 \mathrm{~m})$.
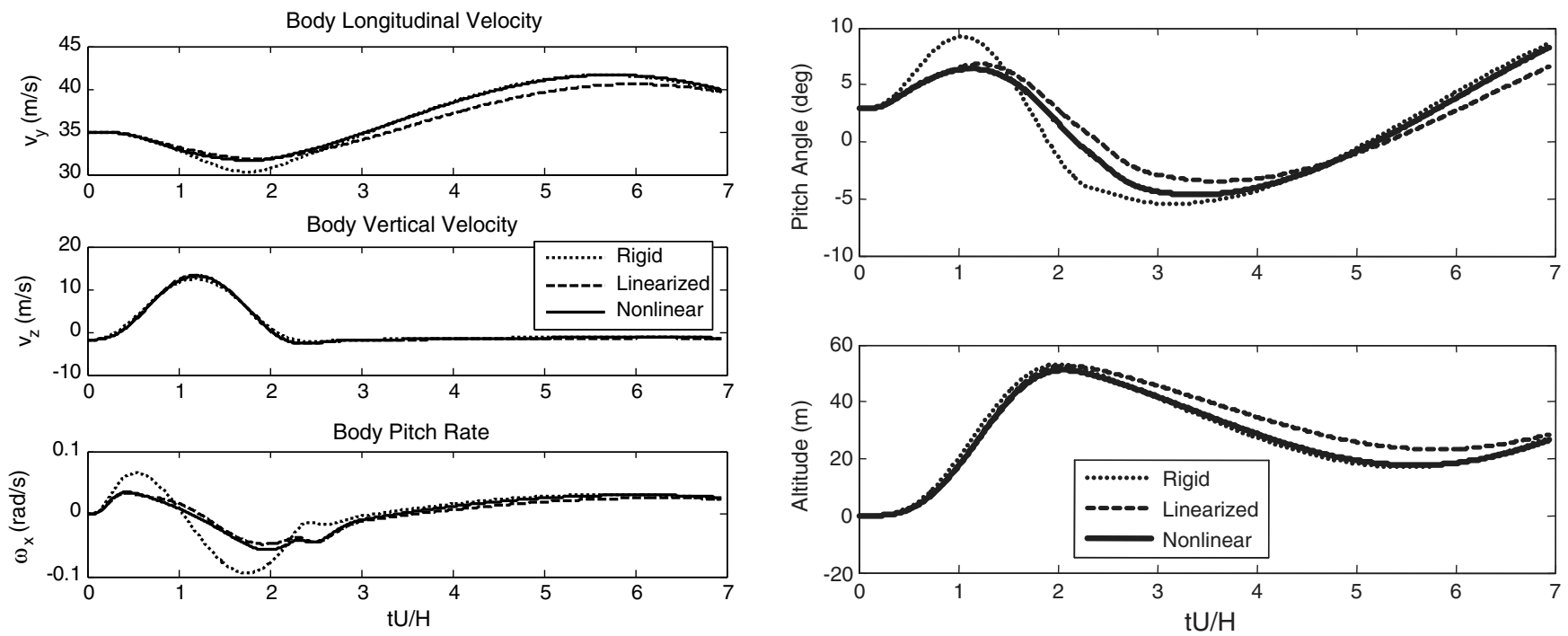

Fig. 15 Longitudinal response to symmetric discrete gust $(U=35 \mathrm{~m} / \mathrm{s}, H=100 \mathrm{~m})$. 
aircraft model including geometrically nonlinear structural effects is compared with the rigid and the linearized models for a faster ( $T=0.5 \mathrm{~s})$ and a slower $(T=2 \mathrm{~s})$ excitation, respectively. The excitation is still relatively small, and the structural dynamic response does not show a significant contribution of the geometrically nonlinear terms in Eq. (1) in the initial response of the vehicle.

In general, aircraft flexibility can only be neglected in flight dynamic analysis when the frequency of the response is below the natural structural frequencies. As has been shown in the previous open-loop simulations, that threshold frequency can be rather low for a very flexible aircraft, easily lying within the frequency range of typical vehicle maneuvers.

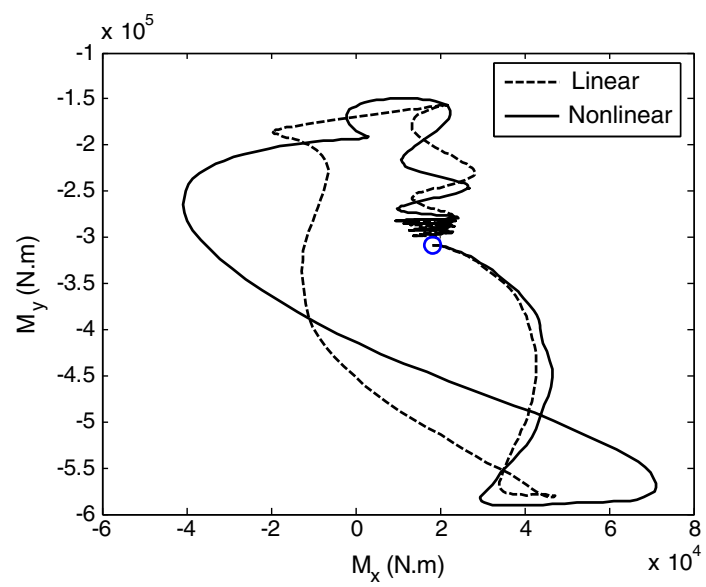

Wing $\operatorname{root}(U=35 \mathrm{~m} / \mathrm{s}, H=25 \mathrm{~m})$

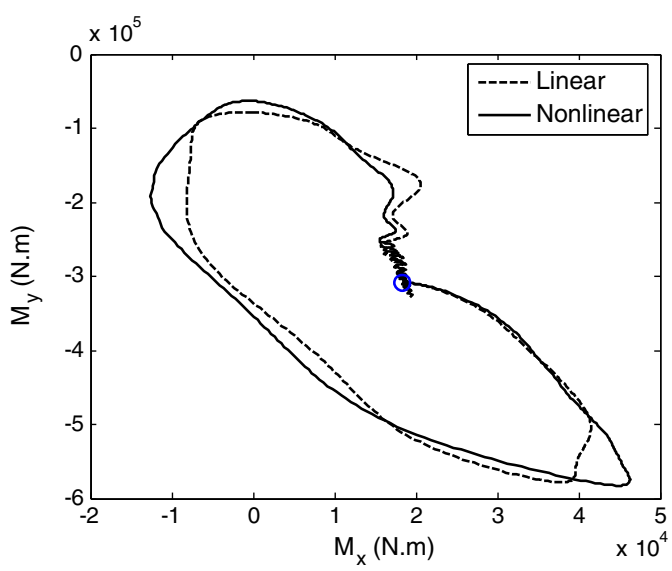

Wing $\operatorname{root}(U=35 \mathrm{~m} / \mathrm{s}, H=50 \mathrm{~m})$

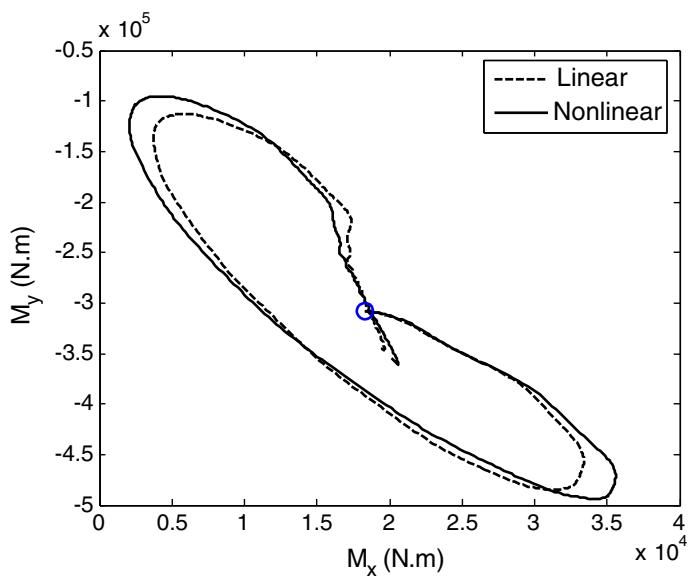

Wing $\operatorname{root}(U=35 \mathrm{~m} / \mathrm{s}, H=100 \mathrm{~m})$

\section{Gust Response}

Gust loads are critical in the design and analysis of very flexible slender-wing aircraft. To illustrate the effect of large structural deformations in the response to typical gust situations, the present configuration is analyzed under a uniform discrete "1-cos" gust distribution. For that purpose, numerical analyses are performed on the trimmed aircraft for steady flight at full nominal weight $\left(M_{P}=1000 \mathrm{~kg} ; M_{F}=2500 \mathrm{~kg}\right)$ and forward flight velocity of $U=35 \mathrm{~m} / \mathrm{s}$. A discrete gust velocity profile is defined as

$$
V_{g}=\frac{1}{2} V_{\mathrm{ds}}\left(1-\cos \frac{\pi s}{H}\right), \quad \text { and } \quad 0 \leq s \leq 2 H
$$

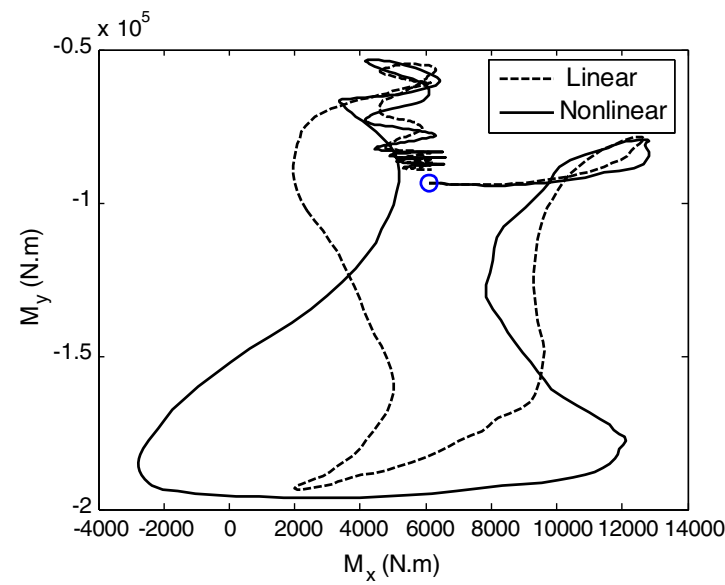

Wing Midpoint $(U=35 \mathrm{~m} / \mathrm{s}, H=25 \mathrm{~m})$

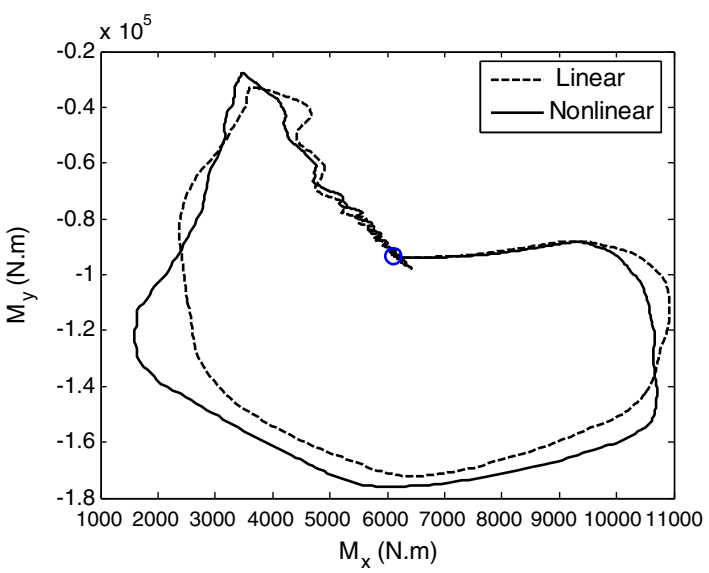

Wing Midpoint $(U=\mathbf{3 5} \mathrm{m} / \mathrm{s}, H=50 \mathrm{~m})$

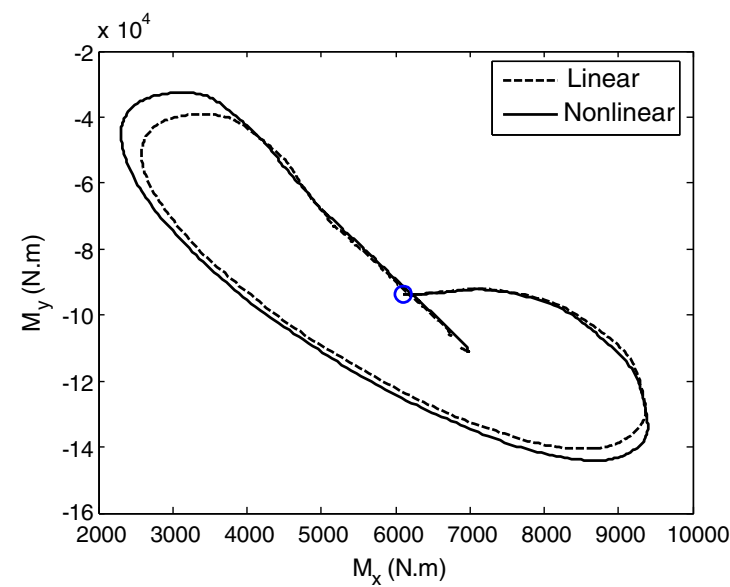

Wing Midpoint $(U=35 \mathrm{~m} / \mathrm{s}, H=100 \mathrm{~m})$

Fig. 16 Bending-twist moment $(M y-M x)$ diagrams in the response to symmetric discrete gust. 
where $V_{\mathrm{ds}}$ is the design gust velocity, and $H$ is the gust gradient distance. The gust velocity is selected to be $V_{\mathrm{ds}}=15 \mathrm{~m} / \mathrm{s}$, and the gust is fixed in space, with $s$ corresponding to the global coordinate $y$ in Fig. 2, so that the vehicle passes through the gust region as it moves along that direction. As before, the trimmed aircraft corresponds to the nonlinear static equilibrium, and three different aircraft models (rigid, linearized, and geometrically nonlinear) were considered for the structural dynamic response. Numerical integrations were performed with the modified Newmark method with an integration time step of $U \Delta t / H=1 / 50$. Figure 13 shows the nonzero velocities, displacements, and rotations of the reference point (the origin of coordinates of the undeformed configuration in Fig. 2) for a short gust $(H=25 \mathrm{~m})$, whereas Figs. 14 and 15 include those results for $H=50 \mathrm{~m}$ and $H=100 \mathrm{~m}$, respectively. In all cases, $t=0$ corresponds to the point where the foremost point of the wing of the trimmed (deformed) aircraft in steady flight reaches the gust.

The gust loading under consideration (which corresponds to similar conditions as those defined in the Federal Aviation Regulations, Part 25) has a significant impact on the aircraft dynamics, including an important contribution of the aircraft structural dynamics. In addition to that, the flexible vehicle undergoes rather large wing deformations, which results in significant differences in the trajectories followed by the three different models after they hit the gust. In particular, wing deformation absorbs part of the energy of the gust; therefore, the flexible models show smaller peak body values than the rigid aircraft. Since the vehicle on these flight conditions has already been shown to be dynamically unstable, longer simulations in this case would also show an unstable phugoid mode.

The difference between the solution to the linearized and the nonlinear equations can be more clearly seen on the internal moments at the wing root. Figure 16 shows the diagrams of bending $M_{y}$ and torsion $M_{x}$ moments at the wing root for the linearized and the nonlinear aircraft models, and the three different gust conditions that have been considered. The steady-state values $(t=0)$ are marked in the figures with a circle. From the results, it can be seen that the peak values of both moments are larger in absolute value in the geometrically nonlinear simulation. The difference is particularly important for the torsional moments. Therefore, a linear model would underpredict the gust loads on this configuration and could lead to a nonconservative structural design. Since withstanding gust loads are expected to be critical design criteria for this class of vehicles, this situation should be examined in detail when defining acceptable design procedures.

\section{Conclusions}

This paper has presented a brief critical review of some of the aircraft structural design procedures that could be affected in the development of a very flexible slender-wing aircraft. It has focused on evaluating the effect of two phenomena that are usually neglected in more conventional applications: (geometrically nonlinear) large structural displacements of slender wings, and interactions between flexible- and rigid-body dynamics during flight. Previous results, as well as those presented in this paper, suggest that the flexible effects should be considered in most typical flight dynamic situations, as it is hard to decouple both problems at very low frequencies. At the same time, geometrically nonlinear effects need to be used when defining the steady-state baseline for aircraft with wing bending deformations beyond the range where linear theories hold. The need of a geometrically nonlinear structural model in a number of dynamic applications can be still argued, as a linearized dynamic model may be often a good approximation. Results in this paper (as well as those in [29], among others) have shown, however, that for long-term simulations, integration of the small corrections provided by a nonlinear structural model can yield a significant variation in the final position and attitude of the vehicle. It was also shown that the accuracy of the structural model would be important when studying the characteristics of an unstable flight dynamic mode. In the example in the paper, the rate of divergence of the unstable phugoid mode was much larger in a flexible aircraft than it would have predicted by a conventional rigid model, but significant differences were observed in the progress of the instability between a fully nonlinear and a linearized solution.

Gust loads are considered one of the most critical design conditions for very high-aspect-ratio aircraft. For certain tuned gust profiles, the structural displacements may be quite large, as shown in the example in this paper, and the dynamics of the flexible aircraft needs to be computed from the full system of nonlinear equations. Furthermore, for a coupled aeroelastic/flight dynamics problem, one cannot assure that the linearized structural model is going to provide a conservative estimate of the internal loads on the primary structures. A geometrically nonlinear model of the structure seems to be needed in the gust response of very flexible aircraft.

Based on the studies in this work, we can introduce the following three basic recommendations for the development of a design environment for very flexible aircraft:

1) The deformed aircraft geometry, which will depend on the operating (trim) condition, should be the baseline in weight, structural, and stability analyses. That brings, among other things, new dependencies to the database of aerodynamic stability coefficients of the aircraft or a dynamic definition of the aircraft instant center of gravity.

2) The coupling between aeroelasticity and flight dynamics needs to be considered. That means that aeroelastic models should incorporate the rigid-body motion of the vehicle, whereas flight dynamics models should incorporate aeroelastic effects.

3) Transient dynamic simulations should include, in general, large nonlinear displacements of the aircraft. Linear models can be used to obtain dynamic stability characteristics. However, for analysis of the critical load conditions, such as gust response, linear structural theories may not be conservative.

\section{References}

[1] Tilmann, C. P., Flick, P. M., Martin, C. A., and Love, M. H., "HighAltitude Long Endurance Technologies for SensorCraft," Applied Vehicle Technology RTO AVT-099 Symposium on Novel and Emerging Vehicle and Vehicle Technology Concepts, NATO Research and Technology Organization, RTO Paper MP-104-P-26, Brussels, 2003.

[2] Lucia, D., "The SensorCraft Configurations: A Non-Linear AeroServoElastic Challenge for Aviation," 47th AIAA/ASME/ASCE/ AHS/ASC Structures, Structural Dynamics, and Materials Conference, AIAA Paper 2005-1943, 2005.

[3] Livne, E., "Aeroelasticity of Joined-Wing Airplane Configurations: Past Work and Future Challenges-A Survey," 42nd AIAA/ASME/ASCE/ AHS/ASC Structures, Structural Dynamics, and Materials Conference, AIAA Paper 2001-1370, 2001.

[4] Livne, E., and Weisshaar, T. A., "Aeroelasticity of Nonconventional Airplane Configurations: Past and Future," Journal of Aircraft, Vol. 40, No. 6, 2003, pp. 1047-1065. doi: $10.2514 / 2.7217$

[5] "Airworthiness Standards: Transport Category Airplanes," Federal Aviation Admin. Dept. of Transportation Code of Federal Regulations, Title 14, Chap. 1, Part 25, Washington, D.C., Jan. 2004.

[6] "Airworthiness Certification Criteria," Department of of Defense Handbook MIL-HDBK-516B, 2005.

[7] Su, W., and Cesnik, C. E. S., "Nonlinear Aeroelasticity of a Very Flexible Blended-Wing-Body Aircraft," Journal of Aircraft, Vol. 47, No. 5, 2010, pp. 1539-1553. doi: $10.2514 / 1.47317$

[8] Palacios, R., Climent, H., Karlsson, A., and Winzell, B., "Assessment of Strategies for Correcting Linear Unsteady Aerodynamics Using CFD or Experimental Results," edited by Haase, W., Selmin, V., and Winzell, B., Progress in Computational Flow-Structure Interaction, SpringerVerlag, New York, 2001.

[9] Garcia, J. A., "Numerical Investigation of Nonlinear Aeroelastic Effects on Flexible High-Aspect-Ratio Wings," Journal of Aircraft, Vol. 42, No. 4, 2005, pp. 1025-1036. doi:10.2514/1.6544

[10] Murua, J., Palacios, R., and Graham, J. M. R., "Applications of the Unsteady Vortex-Lattice Method in Aircraft Aeroelasticity and Flight Dynamics," Progress in Aerospace Sciences, Vol. 55, Nov. 2012, pp. 46-72. doi:10.1016/j.paerosci.2012.06.001

[11] Love, M., Zink, P., Wieselmann, P., and Youngren, H., "Body Freedom Flutter of High Aspect Ratio Flying Wings," 46th AIAA/ASME/ASCE/ 
AHS/ASC Structures, Structural Dynamics and Materials Conference, AIAA Paper 2005-1947, 2005.

[12] Weisshaar, T. A., and Lee, D. H., "Aeroelastic Tailoring of Joined-Wing Configurations," 43rd AIAA/ASME/ASCE/AHS/ASC Structures, Structural, Dynamics and Materials Conference, AIAA Paper 2002-1207, 2002.

[13] Strong, D. D., Kolonay, R. M., Huttsell, L. J., and Flick, P. M., "Flutter Analysis of Wing Configurations Using Pre-Stressed Frequencies and Mode Shapes," 46th AIAA/ASME/ASCE/AHS/ASC Structures, Structural Dynamics and Materials Conference, AIAA Paper 2005-2173, 2005.

[14] Patil, M. J., Hodges, D. H., and Cesnik, C. E. S., "Nonlinear Aeroelasticity and Flight Dynamics of High-Altitude Long-Endurance Aircraft," Journal of Aircraft, Vol. 38, No. 1, 2001, pp. 88-94. doi: $10.2514 / 2.2738$

[15] Wang, Z., Chen, P. C., Liu, D., and Mook, D., "NonlinearAerodynamics/Nonlinear-Structure Interaction Methodology for a High-Altitude Long-Endurance Wing," Journal of Aircraft, Vol. 47, No. 2, 2010, pp. 556-566. doi: $10.2514 / 1.45694$

[16] Bendiksen, O. O., "Transonic Limit Cycle Flutter of High-Aspect-Ratio Swept Wings," 47th AIAA/ASME/ASCE/AHS/ASC Structures, Structural Dynamics and Materials Conference, AIAA Paper 2006-1635, 2006.

[17] Strganac, T. W., Cizmas, P. G., Nichkawde, C., Gargoloff, J., and Beran, P. S., "Aeroelastic Analysis for Future Air Vehicle Concepts Using a Fully Nonlinear Methodology," 46th AIAA/ASME/ASCE/AHS/ ASC Structures, Structural Dynamics and Materials Conference, AIAA Paper 2005-2171, 2005.

[18] Torenbeek, E., Synthesis of Subsonic Airplane Design, Kluwer Academic, Dordrecht, The Netherlands, 1982, pp. 246-249, 296-297.

[19] Bisplinghoff, R. L., Ashley, H., and Halfman, R. L., Aeroelasticity, Dover, New York, 1996, pp. 474-489.

[20] Tang, D., Dowell, E. H., and Hall, K. C., "Limit Cycle Oscillations of a Cantilevered Wing in Low Subsonic Flow," AIAA Journal, Vol. 37, No. 3, 1999, pp. 364-371. doi: $10.2514 / 2.717$

[21] Kim, K., and Strganac, T. W., "Nonlinear Responses of a Cantilever Wing with a External Store," 44th AIAA/ASME/ASCE/AHS Structures, Structural Dynamics, and Materials Conference, AIAA Paper 2003$1708,2003$.

[22] Drela, M., "Integrated Simulation Model for Preliminary Aerodynamic, Structural, and Control-Law Design of Aircraft," 40th AIAA/ASME/
ASCE/AHS/ASC Structures, Structural Dynamics and Materials Conference, AIAA Paper 1999-1394, 1999.

[23] Su, W., and Cesnik, C. E. S., "Dynamic Response of Highly Flexible Flying Wings," AIAA Journal, Vol. 49, No. 2, 2011, pp. 324-339. doi:10.2514/1.J050496

[24] Patil, M., and Taylor, D., "Gust Response of Highly Flexible Aircraft," 47th AIAA/ASME/ASCE/ AHS/ASC Structures, Structural Dynamics, and Materials, AIAA Paper 2006-1638, 2006.

[25] Peters, D. A., Karunamoorthy, S., and Cao, W., "Finite State Induced Flow Models. Part I: Two-Dimensional Thin Airfoil," Journal of Aircraft, Vol. 32, No. 2, 1995, pp. 313-322. doi: $10.2514 / 3.46718$

[26] Pritchard, J., "Overview of Landing Gear Dynamics," Journal of Aircraft, Vol. 38, No. 1, 2001, pp. 130-137. doi: $10.2514 / 2.2744$

[27] Grouas, J., "A Very Large Aircraft, a Challenging Project for Aeroelastics and Loads," International Forum on Aeroelasticity and Structural Dynamics, Asociacion de Ingenieros Aeronauticos de Espana, Madrid, 2001.

[28] Shearer, C. M., and Cesnik, C. E. S., "Nonlinear Flight Dynamics of Very Flexible Aircraft," Journal of Aircraft, Vol. 44, No. 5, 2007, pp. $1528-1545$. doi:10.2514/1.27606

[29] Shearer, C. M., and Cesnik, C. E. S., "Trajectory Control of Very Flexible Aircraft," Journal of Guidance, Control, and Dynamics, Vol. 31, No. 2, 2006, pp. 340-357. doi: $10.2514 / 1.29335$

[30] Tuzcu, I., Marzocca, P., Cestino, E., Romeo, G., and Frulla, G., "Stability and Control of a High-Altitude, Long-Endurance UAV," Journal of Guidance, Control, and Dynamics, Vol. 30, No. 3, 2007, pp. 713-721. doi:10.2514/1.25814

[31] Cesnik, C. E. S., and Brown, E. L., "Modeling of High Aspect Ratio Active Flexible Wings for Roll Control," 43rd AIAA/ASME/ASCE/AHS/ ASC Structures, Structural Dynamics, and Materials Conference, AIAA Paper 2002-1719, 2002.

[32] Peters, D. A., and Johnson, M. J., "Finite-State Airloads for Deformable Airfoils on Fixed and Rotating Wings," ASME Winter Annual Meeting for Aeroelasticity and Fluid/Structures Interaction Problems, a MiniSymposium, Vol. 44, American Soc. of Mechanical Engineers, New York, 1994, pp. 1-28. 